\title{
Type A behavior in individuals with psoriasis as a determinant of acceptance of illness
}

\author{
Małgorzata A. Basińska, Marta Drozdowska
}

Institute of Psychology, Kazimierz Wielki University, Bydgoszcz, Poland

Head: Prof. Janusz Trempała

Postep Derm Alergol 2012; XXIX, 6: 432-439

DOI: $10.5114 /$ pdia.2012.32390

\begin{abstract}
Introduction: Type A behavior (TAB) pattern is a complex of behavioral characteristics or a life style expressing excessive vigilance, aggressiveness, excitability, inclination to compete and a feeling of time pressure and excessive responsibility. It is known to be a risk parameter of somatic illnesses and affects the course of disease.

Aim: To qualify the relation between TAB and acceptance of illness ( $\mathrm{Al}$ ) in a group of individuals with psoriasis. Material and methods: The sample included 60 patients with psoriasis. Patients were subjected to three testing methods: Framingham Type A Behavior Pattern Measure, Acceptance of Illness Scale and a personal survey.

Results: The results show differences in the intensity of a typical subcomponent of TAB pattern, time urgency, between healthy women and diseased men and between women and men in the diseased group of people. Women, in comparison to men, are predisposed to time urgency regardless of their health condition. The clinical state of diseased people does not differentiate the level of TAB. In the group of women with psoriasis there is a negative correlation between a tendency to follow the TAB pattern and its subcomponent time urgency and Al. Diseased women with a lower Al have a higher predisposition to functioning according to TAB. Type $A$ is related to functioning in the state of illness by Al.

Conclusions: Type A behavior plays the role of a risk predictor in the investigated group, but its role as a risk predictor of psoriasis requires further research.
\end{abstract}

Key words: psoriasis vulgaris, PASI, daily food rations.

\section{Introduction}

The concept of the type A behavior pattern (TAB) was formulated by M. Friedman and R.H. Rosenman. These scientists, based on conducted research and their clinical practice of treating patients with cardiological illnesses, have observed that people who suffer from heart attacks are distinguished by a specific way of behavior. They are constantly engaged in a permanent drive to achieve as many goals as possible in the shortest possible time, overcoming potential obstacles from other people or circumstances. These individuals have a strong tendency to compete, and crave appreciation and promotion [1].

Moreover, the influence of TAB as a risk factor in many other somatic diseases such as alimentary disorders [2] or rheumatologic joint inflammation in a male group [3] has been proven. The results of studies presented in the professional literature did not confirm any connection between $\mathrm{TAB}$ and morbidity rates of ischemic heart disease $[2,4]$.
It has been partly proven that TAB is a risk factor in numerous diseases. Therefore a question of it being one of the risk factors in psoriasis arises, as well as its relation to functioning during the illness by way of illness acceptance.

\section{Type A behavior}

Human behavior is a result of interaction between personality and situational variables. An individual with a certain type of personality perceives and estimates a situation in a certain way, which contributes to the person's behavior. Personality conditions the choice of lifestyle, and may lead to the creation of internal and external conflicts, as well as influencing an individual's behavior in conflict situations.

The description of TAB has been numerously modified and finally has been defined as: a form of behavior or a lifestyle defined as a group of public behaviors or a lifestyle

Address for correspondence: Małgorzata Anna Basińska PhD, Institute of Psychology, Kazimierz Wielki University, 1 Staffa St, 85-870 Bydgoszcz, Poland, phone: +48 5237084 00, fax: +48 5237084 02, e-mail: malbasinska@wp.pl 
characterized by extreme competition, drive for achievements, aggression, haste, impatience, excitability, excessive vigilance, vigorous way of speaking, face muscle tension, feeling of time pressure and excessive responsibility [5].

Certain contents and features of TAB can be distinguished. For the contents, these are: a strong urge for achievements (ambitious goals, rivalry, competing), tendency to domination (showing initiative in a group, having control over surroundings) as well as aggression (often of some instrumental character, connected with fighting obstacles). Formal features of TAB are: highly dynamic behavior, energetic performance, haste and impatience [2].

The most essential components of TAB are tendency to compete and time urgency. They are accompanied, with different frequency and intensity, by negative emotions that can be significant factors increasing the risk of occurrence of numerous diseases and worse health condition during the course of an illness [6].

Research shows that TAB has no genetic basis, although some of its aspects might be genetically conditioned. It is known that TAB is created during childhood and is characterized by quite significant stability. Therefore, there is a high probability that a child with this type of behavior will present this type of behavior also as an adult. One of the essential factors creating TAB is probably a certain process of upbringing $[5,7]$.

Type A behavior is physiologically and hormonally conditioned. The individual growth in catecholamine release (adrenaline and norepinephrine) for individuals with $T A B$, in comparison to those with type $B$, has been proven. Such growth leads to aggressiveness, anger, tendency to rivalry as well as haste, which are typical for type A. Raised levels of cortisol, testosterone, and higher levels of cholesterol and triglyceride in blood serum, have also been identified in type A individuals [8].

According to research, TAB is harmful for health only when it exists in contradiction to the temperamental profile of behavior of a person (meaning the nervous system type). Highly reactive individuals acquiring TAB as a result of external pressures act against their own possibilities and are subject to overstimulation, which can lead to a somatic disease. However, low reactivity people, who require stronger stimulation, are usually not in danger of these negative consequences, as their biological equipment (temperamental traits) and TAB features are compliant [5, 9].

Functioning according to TAB has numerous benefits for a person's life and therefore is difficult to modify. In today's world, living under pressure of time, rivalry and ambitions enable one to achieve professional successes. It is part of economic, professional and social success. Such a way of life contributes to a stronger feeling of happiness, satisfaction and trust in oneself [10]. This type of behavior not only increases the risk of heart diseases, but is also a source of positive life experience [7].

\section{Relationship between type A behavior and somatic diseases}

For many authors the relationship between $T A B$ and cardiovascular diseases is perceived as the strongest confirmation of a direct dependency between a specific emotional pattern and a certain behavior [2]. However, TAB has turned out to increase also the threat of other somatic diseases.

It has been proven that $T A B$ is a factor raising the probability of cardiovascular diseases. The results of many investigations in his field show that people exhibiting TAB more frequently suffer from these illnesses than the opposite type B group [2]. The investigations following the Framingham Heart Study project and covering both men and women indicate TAB as an independent predictor of ischemic heart disease [11]. It is a factor of significant influence on the course of cardiovascular diseases and their recurrence [4].

Patients with ulcerous disease, similarly to those suffering from cardiac diseases, tend to accumulate emotions after stressful events [12]. Research conducted among patients with ulcerous disease proved the occurrence of features characteristic for TAB. The correlating factors are strong commitment to tasks, responsibility, competing tendencies, strain over professional matters, tendency to a quick manner of speaking and moving, impatience and irritation [5].

Men suffering from rheumatologic joint inflammation obtained results comparable with coronary disease patients. They applied to features characteristic for TAB: dynamic behavior, high responsibility and conscientiousness at work [3].

Diabetologists distinguish certain personality features, characteristic for patients with diabetes, correlating with components of TAB, increasing the risk of cardiovascular diseases. Factors distinctive for a diabetic personality are: aggressiveness, excitability, striving to dominate, suppression of emotions as well as susceptibility to depression. These are features characteristic for TAB [13].

The role played by $T A B$, as one of many risk factors contributing to the occurrence and course of infectious, cancerous and autoimmune diseases, is still an object of investigations. Physiologists, doctors and psychologists studying the risk factors for somatic diseases tend to underline the relation between a type of personality and a disease. Since no research over such relations in the area of skin illnesses, such as psoriasis, acne, or alopecia areata, has been conducted, these problems deserve more attention.

\section{Psoriasis as a chronic autoimmune disease}

The latest investigations show that the nervous system and skin are anatomically and functionally connected. They are both created from ectoderm and have embryonic and anatomical connections. Neuromediators and neurohormones for skin and nervous and immune systems are the same [14]. Moreover, during a stress reaction both 
systems are activated by the hypothalamus-pituitaryadrenal axis. By the vegetative system skin is also linked with psychological processes: emotions, thoughts, imagination [15]. When in fear, the human body reacts with goose-bumps as well as blood vessel constriction leading to paleness. Coupling between a strong emotional experience and skin reaction may cause skin inflammation.

One of the crucial factors making skin changes more intense is stress. Clinical investigations confirmed its role in increasing the release of corticosteroids, suppressing the immune system and intensifying disease prevalence [16]. The main sources of influence of stress on pathological changes of skin are: the hypothalamus-pituitaryadrenal axis activated by stress, immune modulation induced by stress and a nervous based skin neuropeptide disorder [17].

In recent years many authors have underlined the role neuropeptides play in prevalence of psoriasis $[14,18]$. The most important skin neuropeptides are: substance P (SP), vasoactive intestinal peptide (VIP), calcitonin gene peptide, neuropeptide $Y$, somatostatin, neurotensin, and neurokinin A. It is claimed that these substances are regulatory factors for the nervous and immune system [14, 19].

Faber introduced a new psychoneuroimmune theory of psoriasis formation, claiming that stress increases the amount of SP in skin, brain as well as blood and leads to neurogenic inflammation caused by SP. The authors underline the symmetrical location of psoriatic changes, a retreat of efflorescence after lateral cutting of peripheral nerves as a result of different surgical operations, and strengthening of disease symptoms under the influence of emotional factors [20, 21].

\section{Acceptance of illness}

An emotional determinant of a way of functioning during a disease and a level of adaptation is a degree of acceptance represented by minor, disease connected, negative reactions and emotions. Acceptance equals acknowledgement of limitations. The higher it is, the better the adaptation and the lower the level of psychological discomfort. To accept one's illness is to recognize and to understand the resulting limitation and losses [22].

Patients who have accepted their illness are less likely to experience negative emotions, and their reactions are considerably gentler. They are better adapted and feel less psychological discomfort. These are self-confident, efficient and independent realists [11].

The majority of investigations into disease acceptance have confirmed its positive influence on the health condition of individuals, as well as their quality of life. Research on patients with cancer have indicated that a modification of predicator variables by strengthening acceptance, the feeling of inner health and pain control, may affect ways of dealing with an illness with a negative course, and may increase the adaptation to disease [23]. For lupus ery- thematosus (LE) patients the acceptance of disease and optimism were both a strong predicator of quality of life [24]. This also applies to Graves-Basedow patients, where a relation between intensity of optimism and disease acceptance has been observed [25]. The same phenomenon has been investigated during kidney transplantations, where individuals accepting their health problems functioned better with transplanted organs [22]. In a chronic pain group the acceptance led to lower pain perception [26], and a majority of self-accepting patients with migraine had applied strategies aimed at being creative in life: dealing with pain and reevaluating its experiencing [27]. Acceptance also favors healthy behavior. Diabetics who accepted their situation controlled their metabolism better $[28,29]$ and half of women after a breast amputation underwent supplementary treatment [30].

Taking into account investigations on patients with somatic illnesses, it can be claimed that for the majority of cases the acceptance of illness affects the general state of health as well as helping in functioning in the course of the disease.

Though there are few investigations into conditioning and results of illness acceptance, they indicate two major sources, which are personality and disease characteristics.

The results of conducted research show that for patients with psoriasis disease acceptance correlates with optimism and a belief that others have a minimal influence on their health. It also correlates with a strategy used to deal with stress concentrated on emotions [31].

Wrześniewski underlines a significant negative influence of TAB on somatic disease acceptance, as well as worse functioning during it [32]. Therefore, a modification of pathogenic TAB may lead to undertaking activities beneficial for health, lower the risk of complications and raise the quality of life [4]. For both a Graves-Basedow group [33] and a diabetes group [34], a competitive life attitude hampers disease acceptance.

Acceptance allows proper functioning despite various threats, limitations and problems connected with an illness. The awareness of causes and results of the disease, and potential complications, leads to effective self-control and to applying health beneficial behavior for a better and longer life [35].

\section{Aim}

The aim of the research was to determine the relation between TAB and disease acceptance for a group of patients with psoriasis. Three investigative hypotheses were made:

1. Individuals with psoriasis differ from healthy ones in the intensity of TAB and its components time urgency and rivalry.

2a. Individuals with psoriasis differ in the intensity of $\mathrm{TAB}$ and its components time urgency and rivalry, with regard to health condition expressed in occurrence of complications. 
2b. Individuals with psoriasis differ in the level of disease acceptance with regard to health condition expressed in the occurrence of complications.

3. Type A behavoir and its components time urgency and rivalry show a relation with disease acceptance.

\section{Material and methods}

\section{The studied individuals and the course of investigations}

Study subjects were purposely selected according to health criteria. They were diagnosed with psoriasis by a dermatology medicine specialist. The investigations were conducted individually among members of the Polish National Association of Psoriasis Patients. They were anonymous and voluntary. At the beginning of a meeting the aim and the research related issues were explained and after acquiring the subject's permission, a personal contact was established. The interviewer was to obtain data concerning the patient's health, psychosocial background and the course of the disease. Then, the thoroughly instructed patient filled in the questionnaires.

A group of 60 individuals diagnosed with psoriasis was examined, including 39 (65\%) women and 21 (35\%) men. The average age was $40.2(\mathrm{SD}=12.76)$, with the youngest being 19 years and the oldest 69 years. Moreover, 60 healthy people were examined, selected according to their sex, age and education. Since a scale of disease acceptance is used only for ill individuals, in the healthy group, only two methods were applied: a personal questionnaire and Type A Framingham scale.

Most subjects had secondary education ( $n=24 ; 40 \%)$ or higher ( $n=22 ; 37 \%)$; a minority had vocational $(n=8$; $13 \%)$ or primary education ( $n=6 ; 10 \%)$. Slightly more were single $(n=31 ; 52 \%)$ than married $(n=29 ; 48 \%)$. There were patients without disease complications ( $n=31 ; 52 \%)$, as well as a group with severe complications ( $n=29 ; 48 \%)$ (joint inflammation mainly).

\section{Applied methods}

In order to verify the stated hypotheses the following methods were applied:

\section{Personal questionnaire}

The questionnaire was to collect basic information about the patient: family and professional background, education and health condition: duration of disease, occurrence of complications, diseases in the family and applied methods of treatment.

Type A Framingham Scale of Researched Group - for Framingham Heart Study

The Type A Framingham Scale contains 10 statements, the first five concerning features and characteris- tics of an individual, the next four concerning feelings at the end of an average day, and the last concerning time urgency. The Polish version includes two TAB components hastiness and rivalry.

It is a self-describing tool. The investigation can be conducted individually or in a group among healthy and ill adults. The examined person is to express a personal opinion on all 10 statements. The first 5, concerning individual features, have 4 stages of an answer: 1 - definitely YES; 2 - probably YES; 3 - probably NOT; and 4 - definitely NOT. In positions 6-10, concerning feelings at the end of the day, the examinee is to mark YES or NO.

The high results of a general TAB factor as well as its components (time urgency and rivalry) indicate functioning following the TAB pattern, while low results indicate type $B$ behavior (TBB).

The reliability of the Polish version (Cronbach's $\alpha$ ) of the Type A Scale is 0.62, the standard measurement error 0.02 , with text constancy indicator 0.85 [11].

\section{Acceptance of Illness Scale - AIS B. J. Felton, T. A. Revenson, G. A. Hinrichsen}

The Acceptance of Illness Scale (AIS) was created by Felton and collaborators [28]. It measures the degree of acceptance of illness and it is designed for ill adults (regardless of the kind of disease).

It consists of eight statements, describing the negative consequences of a bad health condition. An examined person is to give an opinion on a current condition using a 5 -grade scale (from 1 - I totally agree, to 5 - I totally disagree) referring to all statements.

Acceptance of illness is due to a lower intensity of negative reactions and emotions connected with current disease. The greater the acceptance, the better is the adaptation and the smaller the psychological discomfort. The AIS has psychometric characteristics at a satisfactory level [11]. The indicator Cronbach's $\alpha$ for the Polish version of the test was 0.82 , with a factor of test constancy 0.69 .

\section{Results}

In order to verify the hypothesis that individuals with psoriasis differ from healthy ones in intensity of TAB and its components time urgency and rivalry, a variance $A$ analysis was conducted.

The findings show no statistically significant differences in the intensity of TAB and its components time urgency and rivalry, for ill and healthy groups (Table 1).

Differences between psoriasis group and healthy group can be seen when sex is taken into consideration (Table 2). Differences concern TAB and its component time urgency.

Post hoc analysis (least significant differences (LSD) test was applied) demonstrated that significant differences concerning TAB occur among ill women, and ill and healthy men, as well as among healthy women and ill men (Table 3). 
Table 1. Student $t$-test results for patients with psoriasis $(n=60)$ and healthy group $(n=60)$ in the level of intensity of $T A B$ and its components time urgency and rivalry

\begin{tabular}{lcccccc}
\hline \multirow{2}{*}{ Type A behavior } & \multicolumn{2}{c}{ Psoriasis } & \multicolumn{2}{c}{ Healthy group } & \multirow{2}{*}{ Value of $p$} \\
\cline { 2 - 6 } & Mean & SD & Mean & SD & & \\
\hline TAB - global result & 0.525 & 0.217 & 0.525 & 0.187 & 0.000 & 0.996 \\
\hline TAB - time urgency & 0.541 & 0.266 & 0.599 & 0.237 & -1.259 & 0.211 \\
\hline TAB - rivalry & 0.519 & 0.219 & 0.455 & 0.211 & 1.627 & 0.106 \\
\hline
\end{tabular}

Table 2. Analyses of variance between women $(n=78)$ and men $(n=42)$ including health condition concerning TAB intensity and hastiness and rivalry

\begin{tabular}{lcc}
\hline Type A behavior & $F$ & Value of $p$ \\
\hline TAB - global result & 3.145 & 0.028 \\
\hline TAB - time urgency & 4.372 & 0.006 \\
\hline TAB - rivalry & 1.847 & 0.143 \\
\hline
\end{tabular}

Table 4. Results (significance levels) of post hoc analysis regarding sex and health condition and time urgency intensity

\begin{tabular}{lcccc}
\hline Time urgency & $\begin{array}{c}\text { Sick } \\
\text { women }\end{array}$ & $\begin{array}{c}\text { Sick } \\
\text { men }\end{array}$ & $\begin{array}{c}\text { Healthy } \\
\text { women }\end{array}$ & $\begin{array}{c}\text { Healthy } \\
\text { men }\end{array}$ \\
\cline { 2 - 5 }$M=0.610$ & $M=0.413$ & $M=0.635$ & $M=0.533$ \\
\hline Sick women & & 0.003 & 0.654 & 0.242 \\
\hline Sick men & 0.003 & & 0.001 & 0.113 \\
\hline Healthy women & 0.654 & 0.001 & & 0.123 \\
\hline Healthy men & 0.242 & 0.113 & 0.123 & \\
\hline
\end{tabular}

Higher TAB is characteristic of women irrespective of their health condition.

Post hoc analysis (LSD was applied) indicated significant differences of time urgency intensity among ill men and ill and healthy women (Table 4). III and healthy women have the strongest tendency to hurry, and ill men have the lowest.

In order to verify hypotheses $2 a$ and $2 b$, stating that in the psoriasis group there occur differences in TAB intensity, its components time urgency and rivalry, as well as
Table 3. Results (significance levels) of post hoc analysis regarding sex and health condition and TAB intensity

\begin{tabular}{lcccc}
\hline TAB & $\begin{array}{c}\text { Sick } \\
\text { women }\end{array}$ & $\begin{array}{c}\text { Sick } \\
\text { men }\end{array}$ & $\begin{array}{c}\text { Healthy } \\
\text { women }\end{array}$ & $\begin{array}{c}\text { Healthy } \\
\text { men }\end{array}$ \\
\cline { 2 - 5 }$M=0.573$ & $M=0.437$ & $M=0.557$ & $M=0.467$ \\
\hline Sick women & & 0.012 & 0.714 & 0.048 \\
\hline Sick men & 0.012 & & 0.026 & 0.623 \\
\hline Healthy women & 0.714 & 0.026 & & 0.093 \\
\hline Healthy men & 0.048 & 0.623 & 0.093 & \\
\hline
\end{tabular}

in the acceptance of an illness judged by health condition regarding complications, Student $t$-test analysis was conducted (Table 5). When comparing ill individuals regarding their health condition, no statistically significant differences were noted.

In order to verify hypothesis 3 , stating the relation between $T A B$, its components time urgency and rivalry, and the acceptance of an illness, Pearson's $r$ correlation test was conducted (Table 6).

There is a statistically significant negative relation between tendency to function according to TAB, and acceptance of illness $(p=0.003)$, meaning that individuals with lower acceptance tend to follow TAB patterns more. Moreover, there was a statistically significant negative relation between tendency to time urgency, and the acceptance of illness ( $p=0.007$ ). Therefore, the lower is time urgency, the easier is acceptance.

In order to state what percentage of acceptance changeability results from TAB (and its component time urgency), a determination factor $\left(r^{2}\right)$ was used, which for the relation between TAB and acceptance is 0.078 . There-

Table 5. Results of Student $t$-test analyses among psoriasis group with $(n=29)$ and without complications $(n=31)$

\begin{tabular}{|c|c|c|c|c|c|c|}
\hline \multirow[t]{2}{*}{ Variable } & \multicolumn{2}{|c|}{ Complications } & \multicolumn{2}{|c|}{ No complications } & \multirow[t]{2}{*}{$t$} & \multirow[t]{2}{*}{ Value of $p$} \\
\hline & Mean & SD & Mean & SD & & \\
\hline Acceptance of illness & 26.000 & 9.134 & 28.871 & 8.766 & 1.242 & 0.219 \\
\hline TAB - global result & 0.549 & 0.235 & 0.503 & 0.201 & -0.812 & 0.420 \\
\hline $\mathrm{TAB}$ - time urgency & 0.563 & 0.271 & 0.521 & 0.265 & -0.605 & 0.548 \\
\hline $\mathrm{TAB}$ - rivalry & 0.531 & 0.242 & 0.508 & 0.198 & -0.403 & 0.688 \\
\hline
\end{tabular}


fore, it can be concluded that this harmful to health TAB is responsible for approximately $8 \%$ of the acceptance changeability. Since the determination factor $\left(r^{2}\right)$ for the relation between time urgency and acceptance is 0.120 , the time urgency is responsible for $12 \%$ of the acceptance changeability in the psoriasis group.

As during hypothesis 3 verification the sex factor was taken into account, Pearson's $r$ test was conducted separately for women and men. There is a statistically significant negative relation for the female group (Table 7) between time urgency and acceptance of illness. The determination factor for the relation between time urgency and acceptance of illness is 0.147, meaning that time urgency is responsible for $14 \%$ of acceptance changeability in the group of women with psoriasis.

For the male group, there is no statistically significant relation between $T A B$, its components time urgency and rivalry, and acceptance of illness (Table 7 ).

Studied patients were later divided according to the median test into a group with lower acceptance of illness $(n=30)$ and a group with higher acceptance $(n=30)$. Then average results in intensity of TAB and its components were compared using Student's t-test (Table 8). Patients with lower acceptance tend to follow TAB patterns more, yet only in the scope of time urgency (Table 8).

\section{Discussion}

The aim of this work was to establish whether TAB is a risk factor for psoriasis and how it is related to functioning in the course of illness judged by acceptance of disease.

The study results show that $T A B$ can be treated as a risk factor for diseases of the circulatory and alimentary sys-
Table 6. Relation among TAB, its components and the acceptance of an illness in psoriasis group $(n=60)$

\begin{tabular}{lccc}
\hline Type A behavior & \multicolumn{3}{c}{ Acceptance of illness } \\
\cline { 2 - 4 } & $r$ & $p$ & $r^{2}$ \\
\hline TAB - global result & -0.279 & 0.321 & 0.078 \\
\hline TAB - time urgency & -0.346 & 0.007 & 0.120 \\
\hline TAB - rivalry & -0.101 & 0.441 & 0.010 \\
\hline
\end{tabular}

tem as well as in rheumatologic joint inflammation. However, data obtained in the present investigation do not prove it to be a risk factor in psoriasis. Patients suffering from psoriasis do not differ from the healthy group in the intensity of behavior characteristic for type A. They differ only in the case of sex, as women were characterized by higher TAB and time urgency. Similar results were obtained in comparison of the healthy group with diabetics type 1 (also auto-aggressive disease) [34] and patients with GravesBasedow disease [33]. Also in these groups levels of TAB and its components hastiness and rivalry were equal. Hence, TAB cannot be treated as a risk factor for patients with psoriasis. Physiological stimulation characteristic for $T A B$ is probably not a relevant factor in the development of psoriasis. However, as the results may be specific only for the examined group, the study requires repetition.

A negative relation between tendency to functioning following $T A B$, its component time urgency and acceptance of illness was observed among women with psoriasis. Patients with lower disease acceptance have a stronger tendency to functioning according to TAB. The lower is time

Table 7. Relation between TAB, its components and acceptance of illness in female and male groups

\begin{tabular}{|c|c|c|c|c|c|c|}
\hline \multirow[t]{3}{*}{ Type A behavior } & \multicolumn{6}{|c|}{ Acceptance of illness } \\
\hline & \multicolumn{3}{|c|}{ Women $(n=39)$} & \multicolumn{3}{|c|}{$\operatorname{Men}(n=21)$} \\
\hline & $r$ & $p$ & $r^{2}$ & $r$ & $p$ & $r^{2}$ \\
\hline TAB - global result & -0.305 & 0.060 & 0.609 & -0.168 & 0.466 & 0.028 \\
\hline TAB - time urgency & -0.384 & 0.016 & 0.147 & -0.234 & 0.307 & 0.054 \\
\hline $\mathrm{TAB}$ - rivalry & -0.137 & 0.406 & 0.018 & -0.007 & 0.977 & 0.001 \\
\hline
\end{tabular}

Table 8. Student $t$-test analysis results for patients with lower $(n=30)$ and higher $(n=30)$ illness acceptance

\begin{tabular}{lccccccc}
\hline Type A behavior & \multicolumn{2}{c}{$\begin{array}{l}\text { Lower acceptance } \\
\text { of illness }\end{array}$} & \multicolumn{2}{c}{$\begin{array}{c}\text { Higher acceptance } \\
\text { of illness }\end{array}$} & Value of $p$ \\
\cline { 2 - 6 } & Mean & SD & Mean & SD & & & \\
\hline WZA - global result & 0.577 & 0.206 & 0.473 & 0.219 & -1.894 & 0.063 \\
\hline WZA - time urgency & 0.609 & 0.257 & 0.473 & 0.262 & -2.025 & 0.047 \\
\hline WZA - rivalry & 0.547 & 0.213 & 0.491 & 0.225 & -0.984 & 0.329 \\
\hline
\end{tabular}


urgency, the easier is acceptance. This indicates a psychological dualism of this group which is inconsistent with previous results [36]. In the course of the illness at the biological level no difference dependent on sex was noted. However, in other investigations with patients suffering from somatic diseases with an auto-aggressive basis, the phenomenon of sexual dualism has occurred both at the biological and psychological level. It also occurs in rheumatologic joint inflammation where male patients more often than female patients have a worse prognosis. What is more, men have higher occurrence of rheumatologic factor ( $\mathrm{RF}+$ ) and their major or axis joints are affected more often, with more severe damage seen in obtained radiographs [3].

In order to verify the obtained results, the investigation ought to be repeated on a larger group. III people do not differ in the intensity of behavior characteristic for type A expressed in the occurrence of complications in the course of illness. This result is consistent with previous research showing high stability of TAB $[7,37]$.

It can be claimed that TAB relevantly influences a patient's functioning in the course of illness as expressed by disease acceptance. In other words, the lower TAB is, the easier is acceptance. This influence mainly concerns time urgency and it is characteristic for female patients only. In statistical analysis sex seems to be an important factor conditioning the course of disease in the studied group $[38,39]$. This conclusion seems to be legitimate, as a lower tendency to hurry can favor concentrating on oneself and the disease, strengthening self-awareness, rational estimation of own possibilities, and noticing positive sides of a situation, consequently leading to higher disease acceptance. Time urgency is usually accompanied by intensification of negative emotions, which can have a negative effect on functioning in the course of disease $[4,6]$.

However, the obtained result differs from Graves-Basedow [33] and diabetes type 1 results [34], where only rivalry affected acceptance, with time urgency having no influence. Therefore, these results may be perceived as specific for psoriasis.

Since difficult life events such as chronic diseases lead to certain changes in lifestyle, it can be cautiously assumed that despite its constancy TAB is subject to certain modifications. Lowering TAB has a positive influence on treatment and reduces mortality in the ischemic heart disease group, with such results concerning mainly men [4]. In the process of psycho-education of psoriasis patients attention should be paid to the pace of their different actions. Treatment during this process ought to be individualized, including differentiation according to sex of patients. Lowering time urgency could help them to accept their illness and to act more constructively for their health.

The research conducted on psoriasis patients leads to the following conclusions:

1. Ill individuals do not differ from healthy ones in the level of intensity of behavior characteristic for TAB.
2. Ill women with a lower acceptance of illness have a stronger tendency to function according to TAB. The lower the time urgency, the easier is acceptance.

3. The disease course with complications is not a factor differentiating the level of TAB and its components.

4. Type A behavior significantly influences a patient's functioning expressed in disease acceptance. The higher the TAB level, the more difficult is acceptance. This influence mainly concerns time urgency.

\section{References}

1. Friedman M, Rosenman RH. Association of specific overt behaviour pat tern with blond and cardiovascular findings. JAMA 1959; 169: 1286-96.

2. Wrześniewski K. Style of life and heath: type A behavior pattern. Wydawnictwo Instytutu Psychologicznego PAN, Warsaw 1993.

3. Basińska MA. Rheumatoid arthritis - the psychological profile. Wydawnictwo UKW, Bydgoszcz 2006.

4. Bętkowska-Korpała B. The role of type A behaviour in prevention of secondary ischemic heart disease. In: Ischemic heart disease. Wrześniewski K, Włodarczyk D (eds). GWP, Gdansk 2004; 175-98.

5. Eliasz A, Wrześniewski K. Risk of psychosomatic diseases. Environment and temperament and pattern of behavior A. Zakład Nauk im. Ossolińskich, Wrocław 1988.

6. Tylka J. Alteration of type A behavior as a base of primary and secondary prevention in ischemic heart disease. Przegląd Psychologiczny 1999; 4: 69-76.

7. Ogińska-Bulik N. Alteration of type A behavior in children. Przegląd Psychologiczny 1999; 4: 83-94..

8. Jarzemowski J. The relation of selected lipid metabolizm parameters in male patients with psychosomatic disease to their behavioural patterns. In: The psychosomatic medicine and psychology of somatic ill in the face of threats and challenges of the civilization of contemporary world. H Skłodowski (ed.). Wydawnictwo Uniwersytetu Łódzkiego, Łódź 1996; 36-40.

9. Ogińska-Bulik N. Type A behavior in children as a favourable health factor? In: Select questions in clinical psychology and personality. In: Psychosomatic. Szewczyk L, Kulik A (eds.). TN KUL, Lublin 2001; 69-78.

10. Czapiński J. Personality of happy man. In: The positive psychology. The knowlegde of happiness, heath, power and righteousness of man. Czapiński J (ed.). Wydawnictwo Naukowe PWN, Warsaw 2005; 359-79.

11. Juczyński Z. The tools of measurement in promotion and psychology of health. Warsaw 2001.

12. Ogińska-Bulik N. The trait of personality and pattern of behaviour as a risk of psychosomatic diseases. Zdr Psych 1994; 1-2: 128-35.

13. Zdzienicka AM. Psychological problems of patients of ill on diabetes. Zdr Psych 1991; 1-4: 173-81.

14. Juszkiewicz-Borowiec M. Contribution of stress in etiopathogenesis of chosen of diseases skin. Przegl Dermatol 1999; 86: 61-5.

15. Miniszewska J, Chodkiewicz J, Zalewska A. Psychodermatology - new challenge for psychology. Nowiny Psychologiczne 2004; 3: 21-9.

16. Dantzer R. Stress and immunity: what have we learned from psychoneuroimmunology? Acta Physiol Scand Supl 1997; 640: 43-6. 
17. Janowski K. Stress and pathobiology of psoriasical processes. Przegl Dermatol 2005; 92: 63-9.

18. Lotti T. Neuropeptides. Skin. JAMA 1995; 33: 482.

19. Misery L. Skin and the nervous system. Br J Dermatol 1997; 137: 843-50.

20. Farber EM. The role of psychoneroimmunology in the pathogenesis of psoriasis. Cutis 1990; 46: 314-6.

21. Rasmy H, Mikhael N, Ismail S. Interleukin-18 expression and the response to treatment in patients with psoriasis. Arch Med Sci 2011; 7: 713-9.

22. Keogh AM, Feehally J. A Quantitative study comparing adjustment and acceptance of illness in adults on renal replacement therapy. ANNA J 1999; 26: 471-7.

23. Juczyński Z. Psychological predictors of adaptation to neoplasmic disease. Psychoonkologia 1997; 1: 3-10.

24. Miniszewska J, Juczyński Z, Sysa-Jędrzejowska A, et al. Quality of life predictors among patients suffering from systemic lupus erythematosus. Przew Lek 2006; 63: 188-90.

25 Basińska MA, Zalewska-Rydzkowska D, Wolańska P, Junik R. Dispositional optimism and acceptance of illness among a group of individuals with Graves-Basedow's disease. Endokr Pol 2008; 59: 23-9.

26. Rankin H, Holttum S. The relationship between acceptance and cognitive representations of pain in participants of a pain management programme. Psychol Health Med 2003; 8: 329-34.

27. Rolka H, Krajewska-Kułak E, Kułak W, et al. Acceptance of disease and coping with pain as essentials components of quality with life in patients with migraine. Preliminary study. Probl Piel 2009; 17: 178-84.

28. Felton BJ, Revenson TA. Coping with chronic illness: a study of illness controllability and the influence of coping strategies on psychological adjustment. J Consul Clin Psychol 1984; 3: 343-53.

29. Harrison T, Stuifbergen A, Adachi E, Becker H. Marriage, impairment and acceptance in persons with multiple sclerosis. West J Nurs Res 2004; 26: 266-85.

30. Nowicki A, Ostrowska Ż. Disease acceptance in patients after surgery from breast cancer during supplementary treatment. Pol Merkuriusz Lek 2008; 143: 5-9.

31. Zalewska A, Miniszewska J, Chodkiewicz J, Narbutt J. Acceptance of chronic illness in psoriasis vulgaris patients. JEADV 2007; 21: 235-42.

32. Wrześniewski K. The role of psychological variables in the development of somatic diseases: proposal of the integrational model. Pol Tyg Lek 1989; 44: 443-5.

33. Basińska MA. Type A behavior in individuals with GravesBasedow disease as a predictor of acceptance of the illness. Polskie Forum Psychologiczne 2011; 16: 29-43.

34. Głowacki SM. Type A behavior in individuals with diabetes type 1 and their functioning in disease. Wydziat Pedagogiki i Psychologii. UKW, Bydgoszcz 2007.

35. Bishop GD. Heath psychology. Wydawnictwo Astrum, Wrocław 2000.

36. Miniszewska J, Walęcka-Matyja K. The determinants of acceptance of disease in haemophilia and psoriasis - the preliminary report. XXXII Zjazd Naukowy Polskiego Towarzystwa Psychologicznego, Kraków 2005.

37. Bergman LR, Magnusson D. Type A behaviour: a longitudinal study from childhood to adulthood. Psychosom Med 1986; 48: 134-42.

38. Boers M. Does sex of rheumatoid arthritis patients matter? Lancet 1998; 352: 419-20.

39. Lockshin MD. Why do women have rheumatic disease? Scand J Rheumatol Suppl 1998; 107: 5-9. 